\title{
Interdisciplinaridade e formação docente
}

Alexandre José Hahn

Junior Bufon Centenaro

FAVERO, A.; TONIETO, C.; CONSÁltER, E. (Orgs.). Interdisciplinaridade e formação docente. Curitiba: CRV, 2018.

Pesquisar sobre uma temática de tamanha envergadura e polissemia como a interdisciplinaridade não é uma tarefa simples, ainda mais quando ela está se constituindo em um campo de conhecimento próprio. Sendo assim, tocar no assunto exige cautela e rigorosidade intelectual, visto que a interdisciplinaridade não se resume apenas a uma ponte entre saberes como comumente é acatada. Não é uma questão de deslocamento, mas de vinculação, de atitude, de um olhar cruzado entre o que se sabe e o que se pode aprender com outros sujeitos e outros saberes; em sua gênese, podemos explicitar que a interdisciplinaridade "busca uma nova forma de compreensão a respeito do conhecimento e sua produção" (p. 11). Nesta perspectiva, traçando alternativas ao trabalho disciplinar, a coletânea Interdisciplinaridade e formação docente (FÁVERO; TONIETO, CONSALTÉR, 2018) põe em diálogo o desafio da formação docente nos mais diversos aspectos.

A obra é fruto de estudos e investigações, realizados entre 2016 a 2018, pelo Grupo de Estudos e Pesquisa em Educação Superior (GEPES) da Universidade de Passo Fundo (UPF), a partir do projeto de pesquisa Interdisciplinaridade, Docência Universitária e Políticas Educacionais. Nos estudos destes três eixos norteadores da pesquisa se "busca a compreensão dos fundamentos epistemológicos e paradigmáticos que perpassam a formação docente na perspectiva da interdisciplinaridade, suas 
possibilidades e suas possíveis consequências para os processos formativos" (p. 13). A obra constitui uma coletânea de artigos que tem como protagonistas, pesquisadores do PPGEdu/UPF e de outros PPGs, doutores convidados do exterior (México e Argentina), doutorandos, mestrandos, bolsistas de iniciação científica, professores da educação básica e da educação superior.

A obra poderia ser definida a partir da seguinte pergunta: quando falamos em interdisciplinaridade falamos especificadamente no quê? Se valendo das investigações de vários pesquisadores, nos mais variados campos do conhecimento, da arte a educação, do meio ambiente a saúde, os organizadores destacam que a interdisciplinaridade pode tanto ser usada como substantivo como também pode ser cunhada como adjetivo. Sommerman (2015), demonstrou que o termo interdisciplinar "aparece como substantivo em 1874 e como adjetivo em 1890; em artigos como substantivo começa a aparecer na década de 1970 e como adjetivo na década de 1980" (p. 11). Na qualidade de substantivo, o termo procura nomear, enquanto como adjetivo tem uma pretensão de qualificação. Nesta conformidade, Sommerman demonstra que nas primeiras pesquisas realizadas quanto a interdisciplinaridade se somavam os esforços ao ato de nomear e também para qualificar uma "nova forma de articulação entre as disciplinas (forjadas historicamente na tentativa de organizar o conhecimento produzido) de modo a contribuir para o avanço do conhecimento" (p. 11). A partir destas iniciativas foi possível pensar e traçar possibilidades de ação para além dos meios monodisciplinar (uma disciplina), multidisciplinar (várias disciplinas sem trocas de saberes entre si) e pluridisciplinar, fomentando práticas que consigam ir muito além das trocas pontuais e eventuais (quase que programadas para acontecer) e da mera difusão tradicional do conhecimento. Daí então que se passa a falar em pesquisas, projetos e sujeitos interdisciplinares.

Convém ressaltar, antes de apresentar os estudos da obra, que a interdisciplinaridade não tem por propósito culminar ou resultar em uma nova disciplina ou em um novo campo do conhecimento, apesar disto poder 
acontecer em razão de uma grande dependência que os saberes podem convenientemente adquirir em suas empreitadas (p. 12). Nos estudos de Sommerman (2015, p. 208), dá-se destaque para a razão conceitual da interdisciplinaridade não apenas num significado único e absoluto, mas plural em suas realizações, podendo ser definido ora por "interação entre as disciplinas de forma coordenada e prolongada" em prol da solução de um problema determinado e complexo dado para além das possibilidades tradicionais, ora por "integração dos discursos", como também "criação de uma terminologia comum", ou "formulação de uma metodologia comum" ou ainda, como destacamos acima, caberia a "geração de um conhecimento novo".

Conforme destacado até aqui, não há como fugir da questão conceitual se quisermos falar ou trabalhar com a interdisciplinaridade, ou melhor dizendo, não se pode objetivamente caminhar interdisciplinarmente sem antes responder a árdua pergunta posta inicialmente: quando falamos em interdisciplinaridade falamos em específico de quê? Os artigos que compõem a coletânea aqui resenhada, demonstram valioso compromisso em adentrar em questões relativas a nossa cultura educacional e seus aspectos formativos. Na sequência, apresenta-se brevemente cada capítulo da coletânea, com o intuito de motivar possíveis leitores a mergulhar profundamente nas propostas e reflexões que demarcam a Interdisciplinaridade e a formação docente.

Os trabalhos iniciam com o texto Interdisciplinaridade e formação de professores: entendimentos e perspectivas, em que Gionara Tauchen e Rafaele Rodrigues de Araújo procuram clarear questões referentes às perspectivas formativas que perpassam os cursos de licenciatura interdisciplinares nas instituições brasileiras de Educação Superior. Especialmente no tocante às Ciências da Natureza. Através de uma análise das políticas educacionais voltadas aos cursos interdisciplinares, os autores demonstram o dilema da formação e as dificuldades de se pensar novas formações para novos professores, uma vez que o professor precisa se reinventar. Enquanto alguns professores criticam a criação das licenciaturas 
interdisciplinares "alegando que o reducionismo de disciplinas em áreas pode ser um retrocesso histórico" (p. 24), outros se sentem desafiados a ir além de uma formação disciplinar, dispostos "a construir com o outro o conhecimento, as estratégias e a compreensão de contextos diferenciados" (p. 24). Conforme os autores, apesar da interdisciplinaridade estar presente na proposição e na indução de novos currículos universitários, ainda se necessita de pensar mais profundamente a organização de estratégias pedagógicas que envolvam princípios de ação capazes de religar os conhecimentos disciplinares.

No segundo capítulo da obra, ligando os conceitos que aludem ao título Interdisciplinaridade e falibilismo na formação docente, Lidiane Limana Puiati Pagliarin e Leandro Carlos Ody constroem uma discussão epistemológica que nos permite pensar possibilidades de progredir intelectualmente. Conforme os autores, enquanto professores e investigadores, "conseguimos construir novos conhecimentos porque cada profissional é especialista em um assunto" e a partir disto é possível "se dedicar melhor ao entendimento de um fenômeno em particular" (p. 49). Entretanto, também produzimos novos conhecimentos porque discutimos com áreas afins, e em virtude disto conseguimos ter um entendimento aprimorado e mais abrangente sobre nosso próprio trabalho, compreendendo de forma mais aguçada tudo que o envolve. Em ambos os aspectos existe um avanço científico, o qual pode ser consequência de dois princípios: “o primeiro deles é que a ciência pode ser questionada, repensada e reelaborada" e o "segundo princípio é que entendemos melhor o fenômeno quando saímos da nossa especialidade e trabalhamos na fronteira com outras áreas do conhecimento" (p. 49). Como é apontado pelos autores, se tratam de duas posturas, a primeira é uma postura falibilista e a segunda interdisciplinar. Diante de uma possibilidade de trabalho mútuo de ambas as perspectivas, os autores procuram responder como tais posturas se fazem presentes na formação docente.

No terceiro capítulo, com o título $A$ interdisciplinaridade na formação continuada de professores: equívocos e possibilidades, Altair 
Alberto Fávero e Evandro Consaltér discutem o uso abusivo do termo interdisciplinaridade no meio educacional, sobretudo no que diz respeito à formação continuada dos profissionais da educação. Os autores demonstram que em virtude de determinados vícios linguísticos, a interdisciplinaridade quase acaba por estar vazia de sentido, assim há uma "necessidade de compreender a interdisciplinaridade em seus fundamentos, com a intenção de analisá-la a partir dos seus elementos constitutivos" (p. 61). Neste propósito, propõem uma limpeza conceitual que facilita (principalmente) aos educadores se livrarem de sérios embaraços quando falam em interdisciplinaridade, seja tanto para as atividades de ensino como para as de pesquisa. Os autores analisam as compreensões possíveis do termo interdisciplinaridade sem fugir da sua origem, a disciplina. Destaque para a seguinte estrofe:

Anular a noção de disciplina, talvez, seja um dos maiores equívocos postulados acerca da interdisciplinaridade nos cursos de formação continuada de professores. Fazenda (1999) entende que o professor deve adquirir conhecimentos de sua própria disciplina para poder contextualizá-los com outras áreas, pois não se pode contextualizar o que não se conhece. O entendimento de disciplina é uma necessidade fundamental para a compreensão do termo interdisciplinaridade (p. 64).

Em seguida, com o intrigante título S.O.S docência interdisciplinaria universitaria, Aristeo Santos López, Marisa Fátima Roman e Lucila Cárdenas Becerril trazem (em língua espanhola) uma reflexão sobre docência e interdisciplinaridade estruturada através de um conciso relato histórico sobre a modernidade. É demonstrado como, a partir do período modernista, o homem acabou por ter uma condição fragmentada de conhecimento que afetou fortemente sua vida intelectual. Esta condição fragmentada, como demonstram os autores, acabou também por influenciar o contexto educacional em que nos encontramos, em especial à maneira docente de agir e refletir. A base do artigo indica como os professores por serem sujeitos de uma cultura, por estarem absortos por determinadas representações, modelos e construções sociais acabam por terem seu 
posicionamento e suas perspectivas impregnadas em paralelo ao paradigma dominante.

No quinto capítulo, A resolução de problemas como prática interdisciplinar na educação: uma proposta epistemetodológica, os pesquisadores Altair Alberto Fávero, Carina Tonieto e Bianca Possel procuram mostrar como a resolução de problemas pode ser uma possibilidade de prática interdisciplinar a partir de uma concepção epistemetodológica. Este último termo é utilizado para enfatizar que "as escolhas metodológicas do pesquisador/professor estão ligadas às concepções epistemológicas” (p. 90), as quais pautam e perpassam tudo que ele faz em suas ações intelectuais. Objetivamente o estudo realizado trata de responder satisfatoriamente a seguinte questão: a concepção epistemológicametodológica da resolução de problemas é uma alternativa promissora para a construção de práticas interdisciplinares na educação? Através deste propósito, os autores nos possibilitam pensar a respeito de alternativas metodológicas que tornem possível a experimentação da interdisciplinaridade no contexto escolar/acadêmico.

Contemplando o sexto capítulo, A perspectiva histórica e política da interdisciplinaridade pelo enfoque da educação, Carmem Lucia Albrecht da Silveira e Munir José Lauer nos levam a uma série de evidências quanto ao caráter histórico e político da interdisciplinaridade no tocante à educação institucionalizada em todos os seus níveis. A questão que permeia o trabalho é: qual é a face política na história da interdisciplinaridade voltada à educação? No decorrer do artigo se demonstra o processo histórico de surgimento da interdisciplinaridade, seguida da orientação ideológica e política fomentada por determinadas agências multilaterais na implantação educacional da interdisciplinaridade.

Procurando responder de que maneira a alteridade e a atitude estética podem contribuir para o desenvolvimento da interdisciplinaridade na prática docente, Carina Copatti e Debora Oliveira Moreira, apresentam o capítulo Interdisciplinaridade e alteridade na educação: interlocuções possíveis numa perspectiva estética. As autoras procuram refletir sobre a constituição 
do sujeito professor a partir de uma formação pautada na alteridade, tomando o entendimento desta como uma possibilidade de interação entre os profissionais da educação. São apresentadas reflexões quanto a atitude estética como uma possibilidade interdisciplinar, frente aos desafios que se apresentam num contexto marcado pela fragmentação do conhecimento. Conforme as autoras, a dimensão estética nas práticas interdisciplinares vai muito além do conhecimento de cada profissional e de sua área específica, pois "permite que, no contato entre eles [mesmos], emerjam elementos que contribuam ao diálogo, para o planejamento conjunto, para a análise de diferentes possibilidades de trabalho" (p. 123). De tal modo, ao mesmo tempo que se possibilita através de um trabalho interdisciplinar aumentar os aparatos do conhecimento, também se pode potencializar experiências sensíveis em relação a questões que surgem do humano, da vida humana e das coisas do mundo.

O oitavo capítulo, de autoria de Alcemira Maria Fávero, Altair Alberto Fávero e Camila Fávero, aborda A vivência teatral como experiência interdisciplinar formativa. Na ótica dos autores, a vivência interdisciplinar articula cognição, atitude, curiosidade, vontade de saber, cooperação, colaboração e horizontalidade entre as áreas do conhecimento. Diante de tal desafio, o texto visa apresentar o teatro como possibilidade de uma experiência interdisciplinar formativa. Para tanto, inicialmente estabelece relações entre sensibilidade, consciência, cultura e criatividade, compreendendo que a sensibilidade enquanto processo de formação se organiza pela organização interna e externa do sujeito com seu entorno. Em seguida, o texto cruza filosofia, arte e antropologia mostrando a relação da criatividade com o trabalho e com a cultura. Na sequência os autores localizam o papel do ator como agente interdisciplinar da arte teatral: "a vida de ator de teatro é uma vida compartilhada e é um trabalho interdisciplinar" (p. 151). O referido texto, devido a sua didática e clareza, contribui para pensar a interdisciplinaridade além dos aspectos cognitivos do sujeito, ao reforçar o papel da sensibilidade e da criatividade na constituição de uma experiência formativa interdisciplinar. 
Francieli Nunes da Rosa e Marta Marques, assinam o nono capítulo da coletânea, A interdisciplinaridade como crítica à fragmentação do saber, objetivando um diálogo com a história para entender os mecanismos que estruturaram a fragmentação dos saberes e a tentativa contemporânea de enfrentamento dessa fragmentação, conhecida como interdisciplinaridade. As autoras demonstram os problemas atrelados ao constante isolamento das disciplinas entre si, gerando entre outras questões, a perda da noção de uma visão global e complexa do conhecimento. Num primeiro momento, reconstroem a partir da abordagem histórico-filosófica, a construção do saber desde o mito até os primórdios da ciência moderna. Na sequência, alguns apontamentos identificam a responsabilidade da ciência moderna com relação a fragmentação, reducionismo e simplificação do saber. Por fim, insistem na necessidade do contexto educacional contemporâneo orientar-se por projetos interdisciplinares atentos a obstáculos epistemológicos e institucionais, psicossociológicos e institucionais, metodológicos, materiais e quanto a formação docente. $\mathrm{O}$ trabalho contribui significativamente para compreender que existem perspectivas epistemológicas que sustentam tanto a fragmentação saber, quanto a interdisciplinaridade. Uma boa apropriação desta última, pressupõe adentrar nos horizontes epistemológicos que a fundamentam.

Interdisciplinaridade e reflexividade na educação escolar, é o décimo capítulo, de autoria de Camile Gasparin e Márcio Luís Marangon. O conhecimento corre o risco de se tornar obsoleto quando pensado somente na ótica da transmissão. Para os autores, em contrapartida a esta percepção está a constituição de uma educação interdisciplinar, com vistas a construção do conhecimento significativo. A herança cultural caracterizada pelo individualismo e hedonismo mostra-se profundamente arraigada na atual geração de educadores, que diante dos percalços atuais da educação vivem mais de uma nostalgia como solução, do que do vislumbre de novas alternativas. A tese defendida no texto é que após realizar o diagnóstico "a reflexividade pode vir a ser um gatilho propulsor de novas perspectivas para a educação" (p. 174). Nas palavras dos autores, "a reflexividade é 
constituinte e fator indispensável à constituição da interdisciplinaridade, desempenhando papel importantíssimo tanto prospectivamente, como retrospectivamente em um projeto" (p. 174).

Monica Vasconcellos e Mylene Cristina Santiago escrevem sobre $O$ potencial freireano e interdisciplinar nos processos formativos: dimensões de ensino, pesquisa e extensão. Como sugere o título, o texto busca compreender o potencial freireano nos processos formativos dos novos professores vinculados ao Programa de Educação Tutorial (PET) vinculado à Universidade Federal Fluminense/RJ. Os pressupostos teóricos e epistemológicos do programa que é definido com interdisciplinar estão articulados com a teoria de Paulo Freire. Os alunos de licenciatura que integram o programa estão imersos "em um processo formativo", que engloba ensino, pesquisa e extensão, tendo como foco a "composição de uma base de conhecimentos ligados ao magistério, em estreita ligação com o espaço escolar, mediante a valorização do diálogo entre os pares, do respeito mútuo, do desenvolvimento da autonomia e da autocrítica” (p. 202). $\mathrm{O}$ estudo torna-se amplamente sugestivo para que sejam estimulados e construídos mais programas desse tipo, com vistas a uma formação de professores num contexto interdisciplinar.

Interdisciplinaridade e educação em direitos humanos: exigências e consequências da complexidade, de autoria de Elias Fochesatto, compõe o décimo segundo capítulo da coletânea. O estudo aprofunda as relações entre as categorias "complexidade" (alternativa para compreender a sociedade contemporânea), "interdisciplinaridade" e "educação em direitos humanos". A Educação em Direitos Humanos é apresentada como uma proposta interdisciplinar, pautada na compreensão da realidade epistemológica e social pelo viés da complexidade. A interdisciplinaridade pode ser um componente essencial para reformar a relação entre ser humano e conhecimento, bastante conturbada após o fortalecimento do paradigma cartesiano. Por fim, o texto afirma que a proposta de Educação em Direitos Humanos conduz o processo educacional e a socialização com vistas a humanização, reconhecimento e dignidade, pois "dimensiona a uma 
reconstrução e reapropriação a partir de uma nova referência: a dignidade da pessoa humana" (p. 222.)

O capítulo doze, A interdisciplinaridade proposta para a educação física a partir das Lições do Rio Grande: o referencial curricular para as escolas estaduais é de autoria de Flaiane Rodrigues Costa. O objetivo do estudo é analisar a maneira como se apresenta a interdisciplinaridade para a educação física no referido documento. $\mathrm{O}$ documento apresenta a interdisciplinaridade como ferramenta para a construção de novos saberes e qualificar o relacionamento entre as várias disciplinas do currículo escolar. A autora busca justificar o entendimento da educação física como pertencente a área de linguagens e suas tecnologias e não a área de ciências da natureza. Um argumento bastante consistente para essa tese é a dimensão da linguagem corporal, um aspecto fundamental para o processo de interação e articulação com as demais disciplinas.

O penúltimo capítulo da coletânea, Educação e Psicanálise, por quê? Considerações sobre a interdisciplinaridade na formação de docentes da educação infantil, é de autoria de Vivian Nolasco. A autora apresenta um relato reflexivo sobre uma experiência interdisciplinar entre educação infantil e psicanálise, a partir de um projeto de formação continuada de docentes. "A importância do enlace das duas áreas do conhecimento reside no fato de que o trabalho com bebês e crianças envolve aspectos inconscientes do docente" (p. 238). O texto demonstra que existem lacunas a serem enfrentadas na construção das competências da atuação docente na educação infantil, pela ausência de estudos sobre subjetividade, intersubjetividade, constituição psíquica, que são conceitos amplamente abordados no campo teórico da psicanálise. O relato da experiência permite compreender os encontros e desencontros entre as duas áreas, assim como o porquê de pensar essa relação interdisciplinar entre ambas.

O professor argentino César Tello escreve o último capítulo com o título La/s política/s educativa/s. Campo teórico y campo de intervención. Sua argumentação se direciona para a necessidade de distinguir a "política educacional" das "políticas educacionais". Para o autor, é comum na 
América Latina se utilizar a expressão "política educacional" para a intervenção dos profissionais na prática, como por exemplo, gestão e administração. Contudo, "política educacional” no singular, está mais ligada ao campo teórico e epistemológico das políticas educacionais; no plural, "políticas educacionais", dizem referência ao campo da prática (gestão, tomada de decisões, ação política). Para Tello, "en ocasiones se comete el error de definir el campo de la política educativa vinculada a adjetivaciones o a la realidad política" (p. 262). O estudo problematiza o fato dos formados em pedagogia ou ciência da educação saírem preparados para o campo da intervenção, mas pouco habituados com a pesquisa do campo teórico denominado de "política educacional".

Em síntese, destacamos que a coletânea Interdisciplinaridade $e$ formação docente está inserida, devido a sua qualidade, no hall de entrada das discussões atuais acerca da interdisciplinaridade na pesquisa em educação. Os interessados em buscar aprofundar a referida obra, encontrarão, a respeito da interdisciplinaridade, importantes razões conceituais e definições terminológicas que salientam a busca por um lugar comum, como também da mesma forma, um reconhecimento de sua pluralidade implícita. Somadas a isto, estão relatadas diversas experiências metodológicas, que por ventura, relevam a possibilidade de efetivação das propostas teóricas e epistemológicas da interdisciplinaridade nos contextos formativos. Levando a cabo que a obra trata de uma temática recorrente do campo da educação, a indicamos para os pesquisadores em políticas educacionais, professores da educação básica e do ensino superior, gestores e administradores dos processos educativos, agentes políticos que atuam na proposição e estruturação das políticas educacionais. Por fim, compartilhamos a mesma esperança dos organizadores de Interdisciplinaridade e formação docente: "que o conjunto desta obra possa orientar um melhor tratamento interdisciplinar no âmbito da educação, permitindo assim, que se possa atenuar os abismos que se criaram entre a teoria e a prática" (p. 19). 


\section{Referências}

FAVERO, A.; TONIETO, C.; CONSÁLTER, E. (Orgs.). Interdisciplinaridade e formação docente. 1. ed. Curitiba: CRV, 2018.

FAZENDA, I. C. Interdisciplinaridade: história, teoria e pesquisa. 4 ed. Campinas: Papirus, 1999.

SOMMERMAN, A. Objeto, método e finalidade da interdisciplinaridade. In: PHILIPPI JR, A. \& FERNANDES, V. Práticas da interdisciplinaridade no ensino e na pesquisa. Barueri/SP: Manole, 2015, p. 165-212.

Submetido em: $15 / 08 / 2019$

Aceito em: 15/09/2019

Publicado em: 30/10/2019 